\title{
Evaluation of a Participatory Research Informed Physical Activity Intervention Among Women from Disadvantaged Neighborhoods - A Pilot Study
}

\author{
Rathi Ramji ( $\nabla$ rathi.ramji@mau.se ) \\ Malmo universitet Fakulteten for halsa och samhalle \\ Margareta Rämgård \\ Malmo universitet Fakulteten for halsa och samhalle \\ Elisabeth Carlsson \\ Malmo universitet Fakulteten for halsa och samhalle

\section{Sergey Shleev} \\ Malmo universitet Fakulteten for halsa och samhalle

\section{Eman Awad} \\ Malmö Högskola: Malmo Universitet

\section{Stefan Criovic} \\ Malmo universitet Fakulteten for halsa och samhalle

\section{Anders Kottorp} \\ Malmo universitet Fakulteten for halsa och samhalle
}

\section{Research article}

Keywords: physical activity, health policy, women, pilot study

Posted Date: October 9th, 2020

DOI: https://doi.org/10.21203/rs.3.rs-87495/v1

License: (c) (i) This work is licensed under a Creative Commons Attribution 4.0 International License. Read Full License 


\section{Abstract}

Background: Citizens living in disadvantaged neighborhoods are susceptible to chronic diseases associated with factors such as physical inactivity and poor nutrition. Women are considered more vulnerable in these situations owing to lack of access to health promotional activities catering their needs. This study aimed at evaluating the effects of a participatory research informed physical activity intervention on the health and related behavior of women living in disadvantaged neighborhoods in Southern Sweden.

Methods: Forty women were invited to participate in a participatory research informed physical activity intervention delivered by health promoters and health ambassadors over a 3-month period. Quality of life was assessed using the WHOQOL-BREF questionnaire and questions regarding behavioral factors including frequency of leisure time physical activity, everyday activities, intake of fruit, vegetable, fish and soda were assessed at three time points including $\mathrm{t} 1$, prior to intervention start, $\mathrm{t} 2$ immediately post-intervention and $\mathrm{t} 3,6$-month post-intervention. Furthermore, biomedical outcomes such as hemoglobin, blood pressure, resting heart rate, blood flow rate, body mass index, fat mass index and muscle mass index were also assessed at the same three time points. Wilcoxon's Sign Rank Test was used to compare pre- and post-test scores.

Results: There was an increase in the scores of the different domains of health related quality of life at t 2 immediately postintervention $(p<.05)$, however the scores reversed at point $t 3$. The behavioral factors including physical activity, everyday activities, and fruit and vegetable intake significantly improved at both follow-up time points post intervention compared to that ahead of the intervention $(\mathrm{p}<.05)$. Systolic and diastolic pressure, significantly decreased at 6 -month follow-up (t3) compared to that at pre- intervention start $(\mathrm{p}<.05)$. There were no significant changes in other biomedical outcomes or behavioral factors.

Conclusion: The participatory research informed physical activity intervention pilot tested among women in disadvantaged neighbourhoods promoted prolonged engagement in physical activity, improved diet and had a positive effect on physical health. However, perceived health seemed to depend on the social interactions among participants during organized group activities indicating that future activities should be of longer duration for achieving sustainable improvements in perceived health.

\section{Background}

Physical activity and nutrition are essential behavioral factors that contribute to overall health and well-being of individuals. Health promotional activities target these behavioral aspects often singularly when aiming to improve health and related quality of life of the population. Previous research has shown the benefits of integrated interventions with focus on both physical activity and nutrition given that food choices are frequently altered in the context of exercise. Further, studies show that individuals tend to choose unhealthy snack directly after exercise thus it was considered important to include nutrition education in physical activity intervention programs [1]. Despite the fact that the World Health Organization (WHO) recommends leisure time physical activity of 150 minutes of moderate intensity aerobic activity per week for adults aged 1864 years nearly $30 \%$ of adults over the age of 15 years are considered to be physical inactive [2]. Evidence suggests that physically inactive individuals are at an increased risk of premature death compared to active individuals [3]. According to a study on the Global Burden of Disease, nearly $4.4 \%$ of the overall burden of disease in populations from European countries was a result of poor nutrition specifically low intake of fruits and vegetables. Issues related to nutrition exist despite the WHO's recommendation of at least five servings of fruits and vegetables as a part of daily routine [4,5]. Physical inactivity on the other hand happens to be the fourth largest cause for death globally, owing to the magnitude of chronic diseases associated with this risk behavior. Aside of its impact on mortality rates, morbidity of health disorders associated with physical inactivity, together with its impact on the health-related quality of life, exerts a substantial economic burden on health systems. Physical inactivity alters body composition and impairs glucose regulation [6]. Previous research also shows that physical inactivity alters rate at which blood circulates in the body, distorts metabolic processes and affects the immune system [7]. 
However, regular physical activity has an impact on controlling body weight and helps regulate blood flow and oxygen saturation in blood [8]. Studies demonstrated that physical activity and healthy diet may help in the reduction of both systolic and diastolic blood pressure up to $5-7 \mathrm{mmHg}$ of especially in otherwise inactive individuals with hypertension [9-11]. Aside of its impact on physical health, prior studies with various cohorts of population, particularly with some form of diagnosis such as different forms of cancer, hypertension, obesity and chronic pain have shown that physical activity helps improve subjective well-being and health related quality of life [12-14]. However, studies addressing the long-term impact of physical activity interventions on the perceived quality of life at a community level are dearth.

The developing countries have been undergoing rapid social and economic transition due to globalization, urbanization, increase in ageing population and most importantly migration, which has benefitted economy through trade exchange and tourism. However, the inevitable results of these structural changes have led to more unhealthy environments; consumption transition and nutritional transition [15]. These transitions particularly have had an impact on socioeconomic factors such as poverty, lack of access to education, which has in turn led to the development of risk behaviors including physical inactivity, as well as, low fruit and vegetable consumption. Interventions targeting such risky behaviors were unable to cope with the pace of the rapidly increasing prevalence of health risk behaviors contributing to the growing prevalence of chronic disease [15].

According to the Swedish national health monitoring and surveillance system nearly $65 \%$ of the Swedish adult population reported to be highly physically active as they followed the recommendation of $150 \mathrm{~min}$ of moderate-intensity physical activity per week since several forms of sports were part of the native Swedish culture [16, 17]. In addition, studies on perception related to physical activity in adult Swedish men showed that there was a general presumption among Swedish natives that being physically active was health, and they also believed that it was associated with good mental health and happiness [18]. However, populations living in low socioeconomic areas in larger cities in Sweden, exhibited low fitness levels due to prolonged sitting owing to lack of access to physical activity, such as sport or training [16]. While physical activity levels is known to differ by age, gender, and disability[19], research also suggests a social gradient associated to it, in that those who are less advantaged often tend to lead a sedentary lifestyle and experience adverse health outcomes related to inactive lifestyle compared to their more advantaged peers [20-22]. The unequal distribution of physical activities both in Sweden and elsewhere is owing lack of access to preventive health care and most importantly lack of access to affordable leisure time physical activity centers or gyms in the neighborhood [23].

Citizens living in socially disadvantaged neighborhoods are often ethnic minorities who differ from the general population by language, cultural beliefs, education levels, and access to the labor market. Lack of adequate efforts towards integration of these communities has led to low social contact, segregation and mental suppression among them. They also face issues such as unemployment and those few that are employed are less informed about employment rights in the host country and tend to have poor work-life balance leading to lack of time for self-care or physical activity [24]. Women belonging to these disadvantaged groups frequently experience more challenges than their male counterparts owing to being financially dependent together with social and traditional values they carried from their country of origin apparently influencing their view of their current context. The rate of chronic disease seemed higher particularly among these women due to their lack of access to knowledge regarding behavioral risk factors and the lack of access to health care services owing to financial and language barriers, resulting in delay in access to primary care, late diagnosis and treatment [17, 24-26].

Interventions targeting the general population fail to reach or rather are not to full advantage to citizens living in socially disadvantaged neighborhoods since their needs in relation to their cultural and contextual factors are seldom considered in the design of these interventions [27]. Thus, there is a need to identify alternate strategies to make otherwise unheard voices heard through directly involving citizens from these community in the design, development and implementation of intervention both globally [24], as well as, in Sweden [28].

Several physical activity interventions targeting this part of the population has been implemented earlier however, their effectiveness in improving health of communities remains uncertain [29]. It has been much debated that such interventions are not customized to the needs of the population in concern and therefore have been unsuccessful [28]. Most of the existing intervention have failed to take into account the views of the target population as done in participatory research informed 
interventions used in health promotional work aiming to reduce health disparities where community members have an active part in developing and implementing interventions [30-33]. Prior research indicates that the participatory research process has the ability to foster productive interaction and multiple impacts since research is co-produced with citizens in concern together with academic, public, and private actors [34-37].

Although participatory research has been the most preferred design in promoting health among citizens residing in socially disadvantaged neighborhoods, assessing the effectiveness of participatory interventions, also calls for appropriate evaluation approaches, considering the resources and time dedicated to develop and implement these interventions [32]. There do exist several physical activity interventions informed by participatory research [30-33]. However, most of these studies were focused on a particular community and were faith-based interventions, where participants were those attending a particular church on selected days of the week $[33,38,39]$. In addition, in most of these studies the level of participation by the target groups in the design and development of the intervention were also not clearly described. Studies evaluating participatory research informed health promotional interventions in the Swedish context is relatively dearth. This may be of particular interest since in a context such as Sweden, a welfare state whose health system has been regarded as a role model for the rest of the world, health inequalities do exists [40]. The health promotional initiatives implemented at a general population level have failed to reach a select group of citizens who live in disadvantaged neighborhoods. Thus, there is a need to apply and evaluate alternative approaches in such context in order to address the remnant health needs of select citizens living in disadvantaged neighborhoods. Previous research also suggests that such health promotional interventions or initiatives aiming to reduce health inequalities must have a cross sectorial approach with the continuous input from the citizens that suffer the most and require help [41], as it is done in participatory research.

One such physical activity intervention program was developed together with the citizens built on a community based participatory research program for strategic planning in a socially disadvantaged neighbourhood in Southern Sweden and tested for its feasibility by the research team [42].The intervention program included both training and physical activity, as well as, reflection, counselling and dialogue regarding healthy diet. The intervention program aimed at introducing gradual change in the lifestyles of the participants beginning with simple bodily movements to more advance exercises in the absence of complex gadgets, which were replaced by everyday objects. The activities were customized based on individual capabilities. The feasibility study gave insights into the development of a contextually appropriate physical activity program. The results of the feasibility study showed that participants perceived an improvement in their health related quality of life after participation. This was also expanded on during the discussions where they associated the sense of happiness to their improved mental health. From the feasibility study, it was also understood that the community members enjoyed physical activity when it was organized in a group where the participants could draw motivation from other members within the group. The participation also increased their sense of security while moving around in the neighborhood since they made new acquaintances through their participation, which in turn extended their social networks within the community. Participation in the intervention program also made participants self-confident and urged them further to share their knowledge with others in their network through becoming coaches themselves. Aside of this all participants were certified as health ambassadors who could spread the intervention to others in the neighborhood [42].

It also appeared that community members preferred training for men and women to be organized separately. The study also brought to light that women in the neighborhood were isolated and there was a need for activities primarily targeting women. In addition, the uptake of interventions were better when offered in a group, as participants perceived that it promoted social bonding and minimized isolation thereby helped building community together with improving health of the citizens. Participants in the feasibility study welcomed the possibility to assess their health using biomedical tests and believed that such tests gave them a realistic evidence of the health impact of the intervention, which further motivated them to be physically active. They were particularly more curious about appearance, body weight and body mass index.

The feasibility study which presented the initial evaluation of the intervention where citizens who were part of the core team for strategic planning and development of the intervention were only included. However, an evaluation of the intervention applied to other citizens who initially participated in the initial Future Workshops and expressed the need for such an activity but were 
not involved in the development of the physical activity intervention was also warranted. However, the feasibility study lacked clarity on the sustainability aspects of the intervention since only the short-term follow-up of the perceptions relating to health related quality of life and some of the biomedical parameters were assessed directly after the end of the intervention.

The aim of the current study was to evaluate the effects of a participatory research informed physical activity intervention on the health and related behaviors of women living in socially disadvantaged neighborhoods in an urban quarter of Southern Sweden.

\section{Methods}

\section{Context}

The intervention program being evaluated in the current study was part of a large health promotional platform informed by participatory research implemented in one of the socially disadvantaged neighborhoods located in Southern Sweden. The Swedish security agency has enlisted this neighborhood as vulnerable due to problems, such as high rate of criminality, low education levels and unemployment. [43]. The citizens living in this neighborhood are predominantly non-Swedish speaking migrants from the Middle east [42].

\section{Study design}

The current study used a longitudinal evaluation design with no control group to assess the health effects of the participatory research informed intervention. Quantitative data in form of surveys and biomedical assessments were gathered over time at three points of time, at first ahead of the intervention, the second measure was precisely after the intervention ended and the third about six months after the intervention. The second follow-up was included since previous studies show that significant changes in biomedical parameters owing to being physically active is often visible at least after a minimum period of six months [44].

\section{Intervention}

The physical activity intervention program being evaluated in the current study was part of a larger project and has been assessed for its feasibility in an earlier study by the authors [42] Future workshops [45] were held together with citizens of the neighborhood, other stake holders and the research team. The workshop gave the opportunity to citizens to express their own needs and help identify strategies to promote health, well-being and quality of life among fellow citizens in their neighborhood. Five problems areas including (a) physical activity, (b) mental health, (c) self-care, (d) oral health and (e) health literacy, emerged from these discussions. Following this some of the citizens and stakeholders together with the academic partners who were facilitators, created a Community Based Participatory research model inspired by a previously proven successful model [37] for strategic planning and implementation of health promotional activities. The citizens of the neighborhood together with the academic partners and other stakeholders identified, developed and implemented health promotional activities in the neighborhood. These health promotional activities were coordinated by select members from the community known as health promoters who had the role of assisting the research team in identifying participants, language interpretation and most importantly to inform the research team about the cultural nuances of the community. The physical activity intervention was based on the perceived need of the community and aimed at building community and diversity through provision of a fair and equal fitness culture among community members. The intervention promoted gradual change through introducing training methods adapted to individual ability. Additionally, citizens taking part in the intervention were certified as health ambassadors who could further spread the intervention to others in the community. The intervention was offered for free with an intention to make it accessible to all members of the community.

The intervention was offered twice a week in two different groups with fifteen to twenty persons in each of the two groups. Each session lasted for about two hours over a period of four months (Fig. 1). The intervention included physical activity indoors and outdoors, as well as dialogue and reflection sessions focusing on other health determinants associated with physical activity such as diet and stress. The health promoters together with some community members who participated in 
the feasibility study and certified as health ambassadors facilitated these sessions. The physical activity intervention not only offered practical training to participants, it also helped women to develop skills to become future trainers. Through being trainers, the participants could spread their knowledge to others in their family and in their neighborhood. Such a method has previously been proven effective in spreading the intervention to larger population groups [46, 47].

\section{Participants}

Three health promoters were involved in participant recruitment for this study. These health promoters initially reached out to about 40 individuals from the neighborhood who were not part of the development of this physical activity intervention [42], but had participated in the initial future workshops. Participants were contacted through face-to-face interactions, as well as, using flyers. There were no specific inclusion criteria for this study as the entire project was grounded in the participatory principles which insists on social inclusion for citizens in the neighborhood. However, in line with the perceptions of citizens that emerged from the feasibility study [42] the current intervention targeted to include as many females as possible, as the feasibility study identified them as most vulnerable group in this community since they were seldom integrated in the society and were not engaged in any form of physical activity. The research team only ensured if participants had any medical or physical restrictions that could hinder their participation. Participants were not requested to follow any particular protocol ahead of the biomedical test which were part of the evaluation study. However, the research team ensured that the participants were tested around the same time of the day at all three-time points (See Fig. 1).

\section{Quality of Life and Behavioral Health Surveys}

Data was collected using a survey evaluating the different domains influencing health related quality of life using the WHO Quality of Life-BREF survey which is a modified version of the WHOQOL-100 [48]. The survey was distributed by the research team together with the health promoter at all three points of time, first before the intervention start at a point $\mathrm{t} 1$, the second immediately after the intervention program ended ( $\mathrm{t} 2$ ) and the third about 6 months after the intervention program ended ( $\mathrm{t} 3$ ). The survey includes 26 items, of which 24 items are grouped into domains namely the physical health, psychological health, social relationships, and environmental domains. The domain scores were calculated from the responses and were later transformed into a 0-100 point scale according to the guidelines of the WHOQOL-BREF [48]. A higher score indicates better quality of life. The questionnaire is available in several languages including Arabic and Swedish. Since most of the participants in this study could only understand Arabic, the Arabic survey was uniformly distributed to the all the participants. The health promoter assisted participants who had difficulties to independently respond to the questions. This survey has been previously validated in 15 different locations and the reliability and validity of the Arabic version has also been assessed in similar population [49]. In addition, the survey was also tested in the feasibility study performed by the research team with participants from the same neighborhood who were involved with the initial development of the questionnaire [42].

Aside of quality of life assessments, participants demographic details such as age, gender, mother tongue, educational qualifications, current employment status, socioeconomic status, as well as, behavioral factors such as diet, physical activity levels, leisure activities were also gathered using standard questions from the national public health survey [50] at the same three points of time when the quality of life assessments were made [42].

\section{Biomedical assessments}

Aside of the self-reported assessments for health made in this study, physical health was also measured using non- invasive biomedical test to assess, blood pressure, restring heart rate, stress index, and vascular age of the heart to understand the effect of physical activity on the cardiovascular functioning. Additionally metabolic risk markers such as body mass index, fat mass, muscle mass and hemoglobin were also assessed non-invasively among all participants at times $\mathrm{t} 1, \mathrm{t} 2$ and $\mathrm{t} 3$. Trained biomedical experts performed the biomedical assessments and were also assisted by health promoters especially for language translation. Aside of language translation health promoters also had the role of being of moral support to the participants. The participants were also informed about the purpose of the different tests and were given the opportunity to understand their own test results together with the biomedical experts. This was done in line with their own perceived needs that emerged in the large workshop, which was the starting point for the development of the physical activity intervention. 
Hemoglobin levels and oxygen saturation in blood were determined non-invasively with the BG20 blood meter from Jones Toptech (Shenzhen, China). The systolic and diastolic blood pressure, as well as the resting heart rate, were measured using an iHealth Sense Wireless Wrist monitor a device from iHealth (California, USA). Blood flow rate and stress index were measured using an AngioScan-01 manufactured by AngioScan-Electronics LLC (Moscow, Russia). Height in centimeters was measured using the MZ10032 device from ADE (Hamburg, Germany). The Tanita Model MC780MA (Tokyo, Japan) was used to perform body composition analysis, i.e. to measure the fat mass, body mass, and body weight. The information on participant's height was entered manually into the Tanita machine to calculate the body mass index. The duration for assessing all the abovementioned parameters was about 40 min, together with the time it took for responding to the surveys, i.e. participants spent about an hour for all the evaluations.

\section{Analysis:}

Before initiation of the study, the sample size was determined by a power analysis based on the feasibility study with fifteen participants who responded to the same questionnaire at two points in time, i.e. before and after the intervention. With an alpha set at 0.05 and power at 0.80 , approximately 35 participants were required to identify a detectable change in the quality of life scores pre-post intervention. As effects based on measures from two follow- ups after the completion of the intervention have not been assessed before, no power calculations could be made, and the analyses will be more exploratory than confirmatory.

As a first step in the analysis all variables, both from the biomedical data and the quality of life scores, were tested for normality. The scores of the four quality of life domains and two global items, the behavioral factors, and biomedical measures were compared in three stages, viz. measures at $\mathrm{t} 1$ prior to invention start $v s$. that of $\mathrm{t} 2$ measured directly at the end of the intervention, followed by $\mathrm{t} 2 \mathrm{vs} \mathrm{t} 3$ measured 6 months after completion of the intervention and, finally, $\mathrm{t} 1 \mathrm{vs}$. $\mathrm{t} 3$. The comparison of median were done using Wilcoxon's Signed Rank Test models [51]. The non-parametric analysis were preferred over parametric analysis although some of the variables were normally distributed due to a small sample size and ordinalbased data in some of the outcome variables. The changes were monitored at group level. Statistical significance was set at a $p$ value of $<0.05$. Effect sizes were finally calculated and interpreted based on reference levels, $d=0.2$ or lower was considered small, $0.2<d<0.5$ as medium, and $d=0.8$ or larger as large [52].

\section{Ethical considerations}

All participants were verbally informed about the intervention program and the purpose of the research study during the first introduction meeting where they were invited to participate in the physical activity program by the health promoters in Arabic language. Participation was voluntary, and the participants were informed that they could leave the study at any point in time without any consequences. All the above information was also provided to the participants in writing together with contact information of the research team both. Participants were asked to sign an informed consent form. All data collected were anonymized, and kept confidential. The data was only accessible to the members of the research team. The Regional Ethical Committee in Lund approved this study (DNR 2018/384).

\section{Results}

Of the 40 females who were invited $35(88 \%)$ of them participated in the intervention program, and the research study. Two of the forty participants, who were invited initially dropped out ahead of the start of the intervention since the training times did not match their individual and family commitments or schedules. Data from three participants were excluded, as they were not present in two of three test occasions when research data were collected. Of the three participants who did not participate in the later stages of the study, one of them had found a job; the other started a fulltime bachelor program at the university and the third moved to a neighboring city. All participant were of Arabic descent, and were aged between 23-77 years. Nearly $29 \%$ of the participants in the group reported to be pursuing further education, mainly language training and about $8 \%$ of the participants reported to be employed and the remaining were homemakers, retired or on parental leave. The demographic characters of participants is presented in Table 1. 
Table 1

Demographic characteristics of participants

\begin{tabular}{|ll|}
\hline Characteristics & $\begin{array}{l}\text { Participants } \\
\text { N }=35\end{array}$ \\
\hline Age & \\
\hline Range $(\mathrm{md})$ & $23-77(49)$ \\
\hline Country of Origin & \\
\hline Irak & $12(33 \%)$ \\
\hline Syria & $8(22 \%)$ \\
\hline Lebanon & $5(14 \%)$ \\
\hline Palestine & $4(11 \%)$ \\
\hline Iran & $4(11 \%)$ \\
\hline Algeria & $1(3 \%)$ \\
\hline Egypt & $1(3 \%)$ \\
\hline Sudan & $1(3 \%)$ \\
\hline Educational Qualification & \\
\hline University education & $7(19 \%)$ \\
\hline High school & $11(31 \%)$ \\
\hline Elementary school & $18(50 \%)$ \\
\hline Employment Status & \\
\hline Employed & $3(8 \%)$ \\
\hline Sick leave & $4(12 \%)$ \\
\hline Parental leave & $1(2 \%)$ \\
\hline Studying/Internship & $10(29 \%)$ \\
\hline Retired & $9(26 \%)$ \\
\hline Home maker & $8(23 \%)$ \\
\hline
\end{tabular}

\section{Health Related Quality of Life}

The Shapiro -Wilk test for normality of the distribution of quality assessments revealed that the physical health domain, psychological health domain, environmental health domain were alone normally distributed $(p<.05)$. The median and range of the WHOQOL-BREF domain scores at the three points of time is presented in Table 2. The participants perceived better health related quality of life directly after participation in the physical activity intervention. The mean score increased by 7 units for physical health, a 10 unit increase in psychological health and over an 8 unit increase in social relationship, and 5 unit increase in perception related to environmental health $(p<.05)$ directly after intervention at point 12 compared to before the start of the intervention $\mathrm{t} 1$. However, there were no significant changes remaining after 6 months after intervention; rather the perceptions reversed after six months of completion of the physical activity intervention at point $\mathrm{t} 3$ and were nearly similar to the perceived scores ahead of intervention start at point $\mathrm{t} 1$. The effect sizes for change in perception of health related quality of life at time point's t1-t2, as well as, t1-t3 were low. The results from the health related quality of life measures in presented in Table 3. 
Table 2

Descriptives of all variables before $\left(t_{1}\right)$, directly after the intervention $\left(t_{2}\right)$ and 6 months post- intervention $\left(t_{3}\right)$

\begin{tabular}{|c|c|c|c|}
\hline HEALTH \& BEHAVIORAL VARIABLES & $t_{1}$ & $t_{2}$ & $t_{3}$ \\
\hline I. Quality of Life Domains \& Global Items & Median (Range) & Median (Range) & Median (Range) \\
\hline Physical Domain $(n=35)$ & $56(19-88)$ & $63(13-94)$ & $56(19-94)$ \\
\hline Psychological Domain $(n=35)$ & $56(25-81)$ & $69(25-94)$ & $56(6-94)$ \\
\hline Social Relationships Domain $(n=35)$ & $56(19-100)$ & $75(44-100)$ & $69(31-100)$ \\
\hline Environmental Domain $(n=35)$ & $56(19-94)$ & $63(25-88)$ & $56(25-88)$ \\
\hline Quality of Life $(n=35)$ & $4(1-5)$ & $4(1-5)$ & $4(1-5)$ \\
\hline Health Satisfaction $(n=35)$ & $3(1-5)$ & $4(1-5)$ & $4(1-5)$ \\
\hline \multicolumn{4}{|l|}{ II. Behavioral Factors } \\
\hline Leisure time Physical activity/training & $1.0(0-5)$ & $3.0(0-5)$ & $3.0(0-5)$ \\
\hline Every day activities $(n=35)$ & $2.0(0-6)$ & $4.0(1-6)$ & $3.0(0-6)$ \\
\hline Hours of sitting $(n=35)$ & $5.0(0-6)$ & $5.0(0-6)$ & $4.0(0-6)$ \\
\hline Vegetable intake $(n=35)$ & $3.0(5.0)$ & $5.0(4.0)$ & $4.0(5.0)$ \\
\hline Fruit intake $(n=35)$ & $4.0(0-5)$ & $5.0(2-6)$ & $5.0(1-6)$ \\
\hline Soda intake $(n=35)$ & $3.0(0-4)$ & $3.0(0-5)$ & $4.0(0-5)$ \\
\hline Fish intake $(n=35)$ & $2.0(1-4)$ & $2.0(1-4)$ & $2.0(0-4)$ \\
\hline \multicolumn{4}{|l|}{ III. Biomedical Parameters } \\
\hline Hemoglobin $(n=25)$ & $156.5(138-161)$ & $155(146-160)$ & $150(125-158)$ \\
\hline Oxygen saturation & $98(92-99)$ & $98(94-99)$ & $98(96-99)$ \\
\hline Systolic blood pressure $(n=31)$ & $126.5(96-162)$ & $117.5(98-164)$ & $123(98-180)$ \\
\hline Diastolic blood pressure $(n=31)$ & $80(55-104)$ & $75(62-98)$ & $74(62-98)$ \\
\hline Resting heart rate $(n=31)$ & $78(60-90)$ & $77.5(60-92)$ & $78(56-96)$ \\
\hline Blood flow rate $(n=25)$ & $329(273-371)$ & $334(295-386)$ & $324(207-385)$ \\
\hline Stress index $(n=31)$ & $199(25-675)$ & $186(6-1087)$ & $252(50-1055)$ \\
\hline Body mass index $(n=31)$ & $30.7(21.7-44.4)$ & $30.5(20.7-43.7)$ & $30.2(20.7-40.8)$ \\
\hline Muscle mass index $(n=31)$ & $46(34.3-61)$ & $46.2(35.6-62.9)$ & $44.6(34-60.7)$ \\
\hline Fat mass index $(\mathrm{n}=31)$ & $27.2(14.2-56.7)$ & $26(12.9-56.6)$ & $28.6(13.4-50.9)$ \\
\hline
\end{tabular}


Table 3

Wilcoxon Signed Rank test comparing quality of life domains and health behavior variables before, directly after the intervention and 6 months after the intervention

\begin{tabular}{|c|c|c|c|c|c|c|c|c|c|}
\hline $\begin{array}{l}\text { HEALTH \& BEHAVIORAL } \\
\text { VARIABLES }\end{array}$ & $\mathrm{t} 2-\mathrm{t} 1$ & & & t3-t2 & & & t3-t1 & & \\
\hline $\begin{array}{l}\text { Mean difference } \\
\text { (SD) }\end{array}$ & z & $\begin{array}{l}\text { Effect } \\
\text { size }\end{array}$ & $\begin{array}{l}\text { Mean } \\
\text { difference }\end{array}$ & z & $\begin{array}{l}\text { Effect } \\
\text { size }\end{array}$ & $\begin{array}{l}\text { Mean } \\
\text { difference } \\
\text { (SD) }\end{array}$ & z & $\begin{array}{l}\text { Effect } \\
\text { size }\end{array}$ & $\begin{array}{l}\text { I. } \\
\text { Quality } \\
\text { of Life } \\
\text { Domain }\end{array}$ \\
\hline Physical Domain & $\begin{array}{l}7.4 \\
(14.1)\end{array}$ & $-2.9 *$ & 0.3 & $\begin{array}{l}-7.4 \\
(14.6)\end{array}$ & $-3.2^{*}$ & 0.4 & $\begin{array}{l}0 \\
(19.1)\end{array}$ & -0.2 & 0.02 \\
\hline Psychological Domain & $\begin{array}{l}10.1 \\
(12.4)\end{array}$ & $-3.9 *$ & 0.5 & $\begin{array}{l}-9.7 \\
(23.6)\end{array}$ & $-2.2^{*}$ & 0.3 & $\begin{array}{l}0.4 \\
(22.9)\end{array}$ & -0.5 & 0.1 \\
\hline $\begin{array}{l}\text { Social Relationships } \\
\text { Domain }\end{array}$ & $\begin{array}{l}8.6 \\
(16.9)\end{array}$ & $-2.9 *$ & 0.3 & $\begin{array}{l}-0.9 \\
(23.3)\end{array}$ & -0.2 & 0.02 & $\begin{array}{l}7.7 \\
(25.7)\end{array}$ & -1.6 & 0.2 \\
\hline Environmental Domain & $\begin{array}{l}5.4 \\
(13.3)\end{array}$ & $-2.3^{*}$ & 0.3 & $\begin{array}{l}-4.9 \\
(12.6)\end{array}$ & $-2.1^{*}$ & 0.3 & $\begin{array}{l}0.5 \\
(14.3)\end{array}$ & -0.6 & 0.1 \\
\hline Quality of Life & $\begin{array}{l}-0.9 \\
(1.2)\end{array}$ & -0.5 & 0.1 & $\begin{array}{l}0.9 \\
(1.0)\end{array}$ & -0.4 & 0.1 & $\begin{array}{l}0 \\
(1.1)\end{array}$ & -0.1 & 0.01 \\
\hline Health Satisfaction & $\begin{array}{l}0.6 \\
(1.1)\end{array}$ & $-3.0 *$ & 0.4 & $\begin{array}{l}-0.5 \\
(1.4)\end{array}$ & $-2.0 *$ & 0.2 & $\begin{array}{l}0.1 \\
(1.6)\end{array}$ & -0.7 & 0.1 \\
\hline \multicolumn{10}{|l|}{ II. Behavioral Factors } \\
\hline $\begin{array}{l}\text { Physical } \\
\text { activity/training }\end{array}$ & $\begin{array}{l}1.4 \\
(1.7)\end{array}$ & $-3.9 *$ & 0.5 & $\begin{array}{l}-0.7 \\
(1.7)\end{array}$ & $-2.2^{\star}$ & 0.3 & $\begin{array}{l}0.8 \\
(1.9)\end{array}$ & $-2.2^{\star}$ & 0.3 \\
\hline $\begin{array}{l}\text { Every day physical } \\
\text { activity }\end{array}$ & $\begin{array}{l}1.4 \\
(2.0)\end{array}$ & $-3.3^{*}$ & 0.4 & $\begin{array}{l}-0.7 \\
(1.7)\end{array}$ & $-2.3^{*}$ & -0.2 & $\begin{array}{l}0.7 \\
(2.2)\end{array}$ & $-2.1^{\star}$ & 0.3 \\
\hline Hours of sitting & $\begin{array}{l}-0.1 \\
(1.2)\end{array}$ & -0.2 & 0.02 & $\begin{array}{l}-0.1 \\
(2.0)\end{array}$ & -0.5 & -0.1 & $\begin{array}{l}-0.1 \\
(2.0)\end{array}$ & -0.6 & 0.1 \\
\hline Vegetable intake & $\begin{array}{l}1.7 \\
(2.0)\end{array}$ & $-4.0 *$ & 0.5 & $\begin{array}{l}-0.7 \\
(1.5)\end{array}$ & $-2.4^{*}$ & -0.3 & $\begin{array}{l}1.1 \\
(2.2)\end{array}$ & $-2.4^{\star}$ & 0.3 \\
\hline Fruit intake & $\begin{array}{l}1.1 \\
(1.7)\end{array}$ & $-3.1 *$ & 0.4 & $\begin{array}{l}0.5 \\
(1.4)\end{array}$ & $-2.1^{*}$ & 0.3 & $\begin{array}{l}1.6 \\
(1.6)\end{array}$ & $-4.4^{\star}$ & 0.5 \\
\hline Soda intake & $\begin{array}{l}0.3 \\
(1.5)\end{array}$ & -1.6 & 0.2 & $\begin{array}{l}0.1 \\
(1.0)\end{array}$ & $-0.5^{\star}$ & -0.1 & $\begin{array}{l}0.4 \\
(1.2)\end{array}$ & -1.8 & 0.2 \\
\hline Fish intake & $\begin{array}{l}-0.2 \\
(0.7)\end{array}$ & -1.4 & 0.2 & $0.1(0.9)$ & -0.1 & -0.01 & $\begin{array}{l}-0.1 \\
(0.8)\end{array}$ & -1.0 & 0.1 \\
\hline
\end{tabular}


Table 4

Wilcoxon Signed Rank test comparing biomedical assessments before, directly after the intervention and 6 months after the intervention.

\begin{tabular}{|c|c|c|c|c|c|c|c|c|c|c|c|c|}
\hline \multirow{2}{*}{$\begin{array}{l}\text { Biomedical } \\
\text { parameters }\end{array}$} & \multicolumn{4}{|c|}{$t 2-t 1$} & \multicolumn{4}{|c|}{ t3-t2 } & \multicolumn{4}{|c|}{ t3-t1 } \\
\hline & $\mathbf{N}$ & $\begin{array}{l}\text { Mean } \\
\text { difference } \\
\text { (SD) }\end{array}$ & $\mathbf{z}$ & $\begin{array}{l}\text { Effect } \\
\text { size }\end{array}$ & $\mathbf{N}$ & $\begin{array}{l}\begin{array}{l}\text { Mean } \\
\text { difference }\end{array} \\
\text { (SD) }\end{array}$ & $\mathbf{z}$ & $\begin{array}{l}\text { Effect } \\
\text { size }\end{array}$ & $\mathbf{N}$ & $\begin{array}{l}\begin{array}{l}\text { Mean } \\
\text { difference }\end{array} \\
\text { (SD) }\end{array}$ & z & $\begin{array}{l}\text { Effect } \\
\text { size }\end{array}$ \\
\hline Hemoglobin & 32 & $-1.2(4.8)$ & $\begin{array}{l}-2.2 \\
\star\end{array}$ & $-0,3$ & 25 & $-5.8(6.4)$ & $-4.0 *$ & $-0,6$ & 25 & $-6.4(7.7)$ & $-3.5^{\star}$ & $-0,5$ \\
\hline $\begin{array}{l}\text { Oxygen } \\
\text { saturation }\end{array}$ & 31 & $0.1(1.7)$ & -0.1 & 0,0 & 31 & $0.3(1.2)$ & -1.3 & $-0,2$ & 30 & $0.4(1.7)$ & -1.0 & $-0,1$ \\
\hline $\begin{array}{l}\text { Systolic } \\
\text { blood } \\
\text { pressure }\end{array}$ & 32 & $\begin{array}{l}-8.2 \\
(14.3)\end{array}$ & $-2.9 *$ & $-0,4$ & 31 & 2.4 (17.9) & $-0.9 *$ & $-0,1$ & 31 & $\begin{array}{l}-5.9 \\
(16.9)\end{array}$ & $-1.8^{*}$ & $-0,2$ \\
\hline $\begin{array}{l}\text { Diastolic } \\
\text { blood } \\
\text { pressure }\end{array}$ & 32 & $\begin{array}{l}-5.0 \\
(10.3)\end{array}$ & $-2.3^{\star}$ & $-0,3$ & 31 & $1.2(11.8)$ & -0.4 & $-0,1$ & 31 & $-3.9(9.7)$ & $-2.2^{*}$ & $-0,3$ \\
\hline $\begin{array}{l}\text { Resting } \\
\text { heart rate }\end{array}$ & 32 & $1.1(7.3)$ & -1.0 & $-0,1$ & 31 & $-1.2(8.4)$ & -1.0 & $-0,1$ & 31 & $-0.5(9.6)$ & -0.2 & 0,0 \\
\hline $\begin{array}{l}\text { Blood flow } \\
\text { rate }\end{array}$ & 32 & $\begin{array}{l}12.9 \\
(27.8)\end{array}$ & $-2.2^{\star}$ & $-0,3$ & 25 & $-19(44)$ & $-2.5^{\star}$ & $-0,4$ & 25 & $-5.4(44)$ & -0.2 & 0,0 \\
\hline Stress index & 30 & $\begin{array}{l}1.6 \\
(221.3)\end{array}$ & -0.1 & 0,0 & 30 & $\begin{array}{l}42.6 \\
(328)\end{array}$ & -1.0 & $-0,1$ & 30 & $\begin{array}{l}42.1 \\
(266)\end{array}$ & -0.4 & $-0,1$ \\
\hline $\begin{array}{l}\text { Body mass } \\
\text { index }\end{array}$ & 31 & $-0.1(0.5)$ & -1.5 & $-0,2$ & 32 & $-0.4(2.2)$ & -0.1 & 0,0 & 31 & $-0.5(2.4)$ & -0.3 & 0,0 \\
\hline $\begin{array}{l}\text { Muscle } \\
\text { mass }\end{array}$ & 31 & $-0.4(1.3)$ & -1.2 & $-0,2$ & 32 & $-0.4(1.5)$ & $-2.1^{\star}$ & $-0,3$ & 31 & $-0.1(1.6)$ & -0.3 & 0,0 \\
\hline Fat mass & 31 & $-0.6(1.0)$ & $-2.7 \star$ & $-0,3$ & 32 & $1.4(5.9)$ & $-2.1^{\star}$ & $-0,3$ & 31 & $-0.1(2.5)$ & -0.5 & $-0,1$ \\
\hline
\end{tabular}

\section{Behavioral Factors}

The Shapiro -Wilk test for normality of the distribution of behavioral factors revealed that none of these factors was normally distributed. The descriptive scores for the different behavioral factors at the three points of time is presented in Table 2. The physical activity intervention also yielded direct and positive significant changes in behavior especially concerning nutrition and fitness (Table 3). After participation in the intervention, the women were significantly more likely to consume more vegetables and fruits $(p<.05)$ than ahead of their participation in the intervention. Although the frequency of intake reduced slightly when enquired again after 6 months after completion of the intervention, the frequency was still significantly higher than the initially reported intake before the intervention start $(p<.05)$. With regards to fitness behavior, the results indicated that participants spent significantly more time on physical activity or training and also reported to have a more active lifestyle in their everyday life $(p<.05)$ directly after participation in the intervention than before. In line with the nutritional aspects, physical activity levels also reversed back at time point t3, 6 months after the structured intervention ended. The levels reported at point $\mathrm{t} 3$ were however, still significantly higher than that ahead of participation in the intervention $(p<.05)$. The intervention did not significantly influence soda intake, fish intake and hours of sitting at all points of time. The effect sizes for change in behavior before and after intervention both at $\mathrm{t} 2$ and $\mathrm{t} 3$ was low to moderate.

\section{Biomedical assessments}


The Shapiro -Wilk test for normality of the distribution of biomedical assessments revealed that diastolic blood pressure, blood flow rate, body mass index, muscle mass index, and fat mass index were alone normally distributed. The descriptive measures for the different biomedical assessments at the three points of time is presented in Table 2. The levels of hemoglobin decreased significantly at time point $\mathrm{t} 2$ and further more at point $\mathrm{t} 3$ compared to time point $\mathrm{t} 1$. Systolic and diastolic blood pressure significantly decreased $(p<.05)$ directly after participation in the intervention when compared to the initial assessment made ahead of the intervention ( $\mathrm{t} 1$ ). The levels were also significantly lower at time point $\mathrm{t} 3$ compared to the first measurement $\mathrm{t} 1(p<.05)$. However, there was no significant difference in diastolic blood pressure between time point $\mathrm{t} 2$ and $\mathrm{t} 3$ and systolic blood pressure significantly increased between time point's $\mathrm{t} 2$ and $\mathrm{t} 3$. Blood flow rate increased significantly directly after participation in the intervention at point $\mathrm{t} 2$ compared to point $\mathrm{t} 1(p<.05)$, the effect reversed after 6 months at point $\mathrm{t} 3$. There was a significant difference in fat mass at time point $\mathrm{t} 2$ compared to $\mathrm{t} 1$ but the effect significantly reversed at point $\mathrm{t} 3(p<.05)$. There were no significant changes in other biomedical parameters assessed both at points $\mathrm{t} 2$ and at $\mathrm{t} 3$ compared to start time t1. The results from the biomedical assessments are presented in Table 5.

\section{Discussion}

In summary, the participants in this study perceived a higher health related quality of life after participation in the intervention program, but the perceived quality of life reversed six months after the organized intervention ended. However, the intervention program seemed to have succeeded in increasing the daily physical activity levels of women from disadvantaged neighborhoods and led to sustained activity even after 6-months post-intervention follow-up period. Similar results were also observed relating to consumption of fruits and vegetables. These behavioral changes were also partly reflected in objective physical health since there was a decrease in the levels of blood pressure, also 6-month post intervention. These results indicate that the participatory research informed physical activity intervention program had a potential impact on some of the important markers of cardiovascular disease. Furthermore, almost all the participants remained actively involved throughout the study despite many training sessions and test occasions, suggesting that an intervention informed by participatory research promotes better participant engagement. This may be because participatory research paradigm not only takes into account citizens' perceived needs but also includes them to be part of the process surrounding the intervention development and implementation

This study demonstrates that participation in the physical activity intervention program also led to sustainable increase in habitual physical activity levels among women in the community who otherwise led a sedentary lifestyle. This is particularly interesting since nearly half of the women were homemakers who lead sedentary lifestyles and seldom had performed physical activity at their leisure before participating in this intervention. Women also became conscious about their diet, and began consuming more vegetables and fruits after taking part in the intervention. The change in physical activity levels together with dietary changes were also reflected on physical health of the participants with significant improvements in risk markers for chronic diseases including blood pressure and glycosylated hemoglobin after participation in the intervention. A few participatory research informed physical activity interventions in adult populations previously implemented and evaluated among populations living in disadvantaged neighborhoods in other countries, have shown similar results relating to health and behavior. However, these studies did not evaluate health using multiple approaches and further did not assess the impact of the intervention over time $[32,53,54]$. The current study on the other hand gave insights on how the intervention influenced both objective physical health and self-reported health in different ways since the results did not concur. Maintainable changes in behaviors related to health and physical health assessed using biomedical tests after the intervention were observed, while self-reported quality of life still seemed to reverse back after the structured intervention ended. Given in these wide differences in the results from the different approaches it may be necessary for future studies to evaluate participatory interventions using multiple approaches using both self-reported instruments, as well as biomedical assessments to understand changes in health when implemented in similar contexts.

The results relating to objective physical health assessed by biomedical tests after the intervention in the current study are also in line with a randomized controlled trial evaluating a culturally adaptive physical activity intervention communities at high risk for cardiovascular disease [55]. The intervention evaluated in the previous study was however, not informed by participatory

Page $12 / 18$ 
research. An earlier review study assessing the impact of interventions targeting health related behaviors also suggest that working with health literacy and knowledge provision helps promote health and change in behavior among community members [56]. The success of the current study may be attributed to the participatory nature, where the citizens themselves set their priorities based on their needs. While other stakeholders and academicians facilitated the knowledge transfer process together with the citizens in a power neutral environment in an attempt to foster empowerment among the citizens which may in turn be a means to long lasting behavioral change [57]. In addition, participants also received more information about the biomedical assessments and their own results, which they frequently missed during their visits to the primary according to results from the feasibility study [42]. This could have further motivated their engagement in both the intervention, as well as the evaluation study.

The results of this study suggests that a four month long intervention was not sufficient to create sustainable changes in perceived health related quality of life which elucidates the association between perceived quality of life and social aspects of training in a group. This also indicates that the percieved health effects of the intervention program may have differed if the structured physical activity program had continued during the time between time point $\mathrm{t} 2 \mathrm{and} \mathrm{t} 3$. Through training in organized groups there was increased social contact between participants within the groups promoting social interaction in otherwise isolated women as shown in the feasibility study [42]. Thus, there may be a need for more systematic group activities which are organized and coordinated by health promotors over time to create a sustainable healthier society. The role of the health promoters may be of particular interest in this since together with facilitating activities they have also been instrumental in bridging between participants and creating a bond between them leading to the formation of a social support network. Earlier studies have also identified the role of social factors in better uptake of physical activity interventions $[17,58,59]$. Aspects such as social support and social networks relate to the concept of social capital, which is the ability of individuals to acquire mutual benefits through being members in certain social networks. This may relate to the case of the current study where performing physical training as a group lead to changes in perceived health acquired with the support of the social network $[60,61]$.

Aside of all of the individual gains participants achieved, they were also certified as health ambassadors on completing the intervention program. As health ambassadors, they could spread the intervention to other members of the community, thereby be instruments for behavioral change at the community level, eventually benefitting the entire neighborhood. This method known as train-the-trainer has been considered effective in increasing public health preparedness at a societal level [47].

\section{Limitations}

Although the results from this study are promising and that there were several both individual and societal benefits, there were also somelimitations. The lack of control group limits the possibility to elaborate on the causal effects of the biomedical findings. The current study did also not entirely follow a participatory approach [37], since participants were only involved with formulating the research question based on their needs but were not part in development of the intervention. In addition, although the participants were involved in the data collection phase in the evaluation process of the current study, they did not have a part in data analysis. The results from the biomedical test should be interpreted with caution since information relating to medications consumed by the participants were not obtained, and could therefore influence the variables measured. Another limitation is large number of missing data in two of the biomedical parameter namely hemoglobin due to technical issues faced while the biomedical assessments were performed. However, previous studies have also identified challenges in conducting invasive health assessments using blood in large groups of populations living in disadvantaged neighborhoods $[62,63]$. Thus, the use of novel non -invasive techniques appears to be a stress-free and less time consuming alternative useful in identifying underlying health problems which may otherwise remain unnoticed in these subgroups of populations. Including only women can be considered as another potential limitation in this study. However, the learnings from the feasibility study indicated that women in these neighborhood are more often isolated and are prone to life style related health problems more often than their male counterparts. In addition, men in the neighborhood had access to several other forms of physical training including gyms and outdoor training facilities unlike women who had traditional restrictions to train in public or together with other men [42]. Although the current study was influenced by a participatory research approach, the citizens from the 
neighborhood were only actively involved in defining the research question based on their own needs, and in the process of identifying potential solutions for implementation and evaluation of activities. It must be noted that they were not part of the research team that analyzed the data or wrote of the manuscript.

\section{Conclusion}

This participatory research informed physical activity intervention program shows a beneficial effect on both physical health and behavior in women from disadvantaged backgrounds. The results from this study suggests that similar initiatives developed in the future, for citizens living in disadvantaged neighborhoods to include long-term organized health interventions that also promotes social interaction and networking among participants for achieving sustainable improvements in perceived health related quality of life. Such an intervention program informed by participatory research may also help minimize the incidence of chronic diseases among citizens in socially disadvantaged neighborhoods and may enhance public health efforts to minimize health inequalities.

\section{Declarations}

\section{Ethics approval and consent to participate}

The Regional Ethical Committee in Lund (DNR 2018/384) approved this study. Written informed consent was obtained from the participants both for participation in the intervention program and the evaluation study. The consent forms can be made available upon reasonable request. The research team ensured that privacy and confidentiality were maintained throughout the study period all personal identifiers were removed ahead of data analysis.

\section{Consent to publish}

All participants consented to publish the results of this study as long as they are anonymous.

\section{Availability of data and materials}

The data from the current study is not publicly available due GDPR regulations but are available from the corresponding author on reasonable request.

\section{Competing interests}

The authors declare no personal, financial or other conflicts neither had competing interest of any form.

\section{Funding}

The study was part of a larger project financed by VINNOVA (DNR 2016-00421, 2017-01272). The VINNOVA funding was primarily towards the establishment of a health promotion platform and did not support research (as that presented in the current study) conducted within this platform. The development of the biomedical testbed used in this study was financed by Knowledge Foundation (Grant No. 20150248).

\section{Authors' Contributions}

All authors including AK, MR, RR, EC, SS, SC and EA participated in the design of the study. RR and MR performed the study apart from biomedical tests, which were performed by EA and SC using a biomedical testbed developed by SS. RR and AK analyzed the data. RR wrote the first version of the manuscript under the guidance of AK, MR and EC. All authors revised, read and approved the final version of the manuscript.

\section{Acknowledgements}


The authors would like to thank the women from the community for participating in this study. The authors would like to extend their deep gratitude to the health promoters Iftikhar Ali, Noha Aldahdouli and Hoda Abbas for their support in coordinating the data collection for this study. We would also like to thank Jörgen Andersson from the Malmö municipality (Malmö Stad) for offering the municipality premises he manages for conducting activities and supporting the research team with practical matters.

\section{References}

1. Koehler, K. and C. Drenowatz, Integrated Role of Nutrition and Physical Activity for Lifelong Health. Nutrients, 2019. 11(7): p. 1437.

2. WHO, W., Global recommendations on physical activity for health. Geneva World Heal Organ, 2010. 60.

3. Katzmarzyk, P., I. Janssen, and C. Ardern, Physical inactivity, excess adiposity and premature mortality. Obesity reviews, 2003. 4(4): p. 257-290.

4. Pomerleau, J., et al., The burden of disease attributable to nutrition in Europe. Public health nutrition, 2003. 6(5): p. 453461.

5. Who, J. and F.E. Consultation, Diet, nutrition and the prevention of chronic diseases. World Health Organ Tech Rep Ser, 2003. 916(i-viii).

6. Eaton, S.B. and S.B. Eaton, Physical Inactivity, Obesity, and Type 2 Diabetes: An Evolutionary Perspective. Research Quarterly for Exercise and Sport, 2017. 88(1): p. 1-8.

7. Nieman, D.C. and L.M. Wentz, The compelling link between physical activity and the body's defense system. Journal of sport and health science, 2019. 8(3): p. 201-217.

8. Joyner, M.J. and D.P. Casey, Regulation of increased blood flow (hyperemia) to muscles during exercise: a hierarchy of competing physiological needs. Physiological reviews, 2015. 95(2): p. 549-601.

9. Carlson, D.J., et al. Isometric exercise training for blood pressure management: a systematic review and meta-analysis. in Mayo Clinic Proceedings. 2014. Elsevier.

10. Diaz, K.M. and D. Shimbo, Physical activity and the prevention of hypertension. Current hypertension reports, 2013. 15(6): p. 659-668.

11. Pescatello, L., Franklin BA, Fagard R, Farquhar WB, Kelley GA, Ray CA. American college of sports medicine position stand. Exercise and hypertension. Med Sci Sports Exerc, 2004. 36: p. 533-553.

12. Joos, B., et al., Influence of an outpatient multidisciplinary pain management program on the health-related quality of life and the physical fitness of chronic pain patients. Journal of negative results in biomedicine, 2004. 3(1): p. 1.

13. Oldervoll, L., et al., Physical exercise results in the improved subjective well-being of a few or is effective rehabilitation for all cancer patients? European Journal of Cancer, 2004. 40(7): p. 951-962.

14. Stewart, A.L., et al., Long-term functioning and well-being outcomes associated with physical activity and exercise in patients with chronic conditions in the Medical Outcomes Study. Journal of clinical epidemiology, 1994. 47(7): p. 719-730.

15. Amiri Farahani, L., et al., Community-based physical activity interventions among women: a systematic review. BMJ Open, 2015. 5(4): p. e007210.

16. Organization, W.H., Physical Activity Factsheets for the 28 European Union Member States of the Who European Region. 2018, WHO Regional Office for Europe Copenhagen.

17. Lindström, M., B.S. Hanson, and P.-O. Östergren, Socioeconomic differences in leisure-time physical activity: the role of social participation and social capital in shaping health related behaviour. Social science \& medicine, 2001. 52(3): p. 441451.

18. Sjörs, C., et al., Perceived Reasons, Incentives, and Barriers to Physical Activity in Swedish Elderly Men. Interact J Med Res, 2014. 3(4): p. e15. 
19. King, A.C., et al., Determinants of physical activity and interventions in adults. Medicine \& Science in Sports \& Exercise, 1992. 24(6, Suppl): p. S221-S236.

20. Cockerham, W.C., B.W. Hamby, and G.R. Oates, The social determinants of chronic disease. 2017, Elsevier.

21. Lissner, L., et al., Social mapping of the obesity epidemic in Sweden. International journal of obesity, 2000. 24(6): p. 801805.

22. Ljung, R., et al., Socioeconomic differences in the burden of disease in Sweden. Bulletin of the World Health Organization, 2005. 83: p. 92-99.

23. Edwards, P. and A.D. Tsouros, Promoting physical activity and active living in urban environments: the role of local governments. 2006: WHO Regional Office Europe.

24. Cooper, L.A., M.N. Hill, and N.R. Powe, Designing and evaluating interventions to eliminate racial and ethnic disparities in health care. Journal of general internal medicine, 2002. 17(6): p. 477-486.

25. Donnelly, T.T., et al., Arab female and male perceptions of factors facilitating and inhibiting their physical activity: Findings from a qualitative study in the Middle East. PLOS ONE, 2018. 13(7): p. e0199336.

26. Aljayyousi, G.F., et al., Addressing context to understand physical activity among Muslim university students: the role of gender, family, and culture. BMC Public Health, 2019. 19(1): p. 1452.

27. Ball, K., et al., Addressing the social determinants of inequities in physical activity and sedentary behaviours. Health Promotion International, 2015. 30(suppl_2): p. ii8-ii19.

28. Heath, G.W., et al., Evidence-based intervention in physical activity: lessons from around the world. The Lancet, 2012. 380(9838): p. 272-281.

29. Lindström, M. and J. Sundquist, Immigration and leisure-time physical inactivity: a population-based study. Ethnicity \& health, 2001. 6(2): p. 77-85.

30. Goh, Y.-Y., et al., Using community-based participatory research to identify potential interventions to overcome barriers to adolescents' healthy eating and physical activity. Journal of behavioral medicine, 2009. 32(5): p. 491-502.

31. Mackintosh, K.A., et al., Using formative research to develop CHANGE!: a curriculum-based physical activity promoting intervention. BMC public health, 2011. 11(1): p. 831.

32. Wieland, M.L., et al., Physical activity and nutrition among immigrant and refugee women: a community-based participatory research approach. Women's Health Issues, 2012. 22(2): p. e225-e232.

33. Wilcox, S., et al., Increasing physical activity among church members: community-based participatory research. American journal of preventive medicine, 2007. 32(2): p. 131-138.

34. Abma, T.A., et al., Social impact of participatory health research: collaborative non-linear processes of knowledge mobilization. Educational action research, 2017. 25(4): p. 489-505.

35. Israel, B.A., et al., Introduction to methods in community-based participatory research for health. Methods in communitybased participatory research for health, 2005. 3: p. 26.

36. Israel, B.A., et al., Review of community-based research: assessing partnership approaches to improve public health. Annual review of public health, 1998. 19(1): p. 173-202.

37. Wallerstein, N., et al., What predicts outcomes in CBPR. Community-based participatory research for health: From process to outcomes, 2008. 2: p. 371-392.

38. Davis, D.S., M.V. Goldmon, and D.S. Coker-Appiah, Using a community-based participatory research approach to develop a faith-based obesity intervention for African American children. Health promotion practice, 2011. 12(6): p. 811-822.

39. Saunders, R.P., et al., Process evaluation methods, implementation fidelity results and relationship to physical activity and healthy eating in the Faith, Activity, and Nutrition (FAN) study. Evaluation and Program Planning, 2014. 43: p. 93-102.

40. Lundberg, O., et al., The role of welfare state principles and generosity in social policy programmes for public health: an international comparative study. The Lancet, 2008. 372(9650): p. 1633-1640. 
41. Lundberg, O., The next step towards more equity in health in Sweden: how can we close the gap in a generation? Scandinavian journal of public health, 2018. 46(22_suppl): p. 19-27.

42. Ramji, R., et al., Development and evaluation of a physical activity intervention informed by participatory research-a feasibility study. BMC Public Health, 2020. 20(1): p. 112.

43. Hallin, P.O., Utsatta områden -sociala risker, kollektiv förmåga och oönskade händelser. 2015, Nationella operativa avdelningen, Underrättelseenheten: Stockholm.

44. Kim, K.M., et al., Efficacy of a new medical information system, ubiquitous healthcare service with voice inception technique in elderly diabetic patients. Scientific reports, 2015. 5(1): p. 1-10.

45. Jungk, R. and N. Müllert, Future Workshops: How to create desirable futures. 1987: Inst. for Social Inventions.

46. Marks, B., J. Sisirak, and Y.C. Chang, Efficacy of the HealthMatters program train-the-trainer model. Journal of Applied Research in Intellectual Disabilities, 2013. 26(4): p. 319-334.

47. Orfaly, R.A., et al., Train-the-trainer as an educational model in public health preparedness. Journal of Public Health Management and Practice, 2005. 11(6): p. S123-S127.

48. Group, W., Development of the World Health Organization WHOQOL-BREF quality of life assessment. Psychological medicine, 1998. 28(3): p. 551-558.

49. Ohaeri, J.U. and A.W. Awadalla, The reliability and validity of the short version of the WHO Quality of Life Instrument in an Arab general population. Annals of Saudi medicine, 2009. 29(2): p. 98-104.

50. Folkhälsoinstitut, S., Nationella folkhälsoenkäten-Hälsa på lika villkor. 2012.

51. Woolson, R., Wilcoxon signed-rank test. Wiley encyclopedia of clinical trials, 2007: p. 1-3.

52. Cohen, J., Statistical power analysis for the behavioral sciences. 2013: Routledge.

53. Sharma, S., Assessing diet and lifestyle in the Canadian Arctic Inuit and Inuvialuit to inform a nutrition and physical activity intervention programme. Journal of Human Nutrition and Dietetics, 2010. 23: p. 5-17.

54. Pazoki, R., et al., Effects of a community-based healthy heart program on increasing healthy women's physical activity: a randomized controlled trial guided by Community-based Participatory Research (CBPR). BMC public health, 2007. 7(1): p. 216.

55. Rosas, L.G., et al., Evaluation of a culturally-adapted lifestyle intervention to treat elevated cardiometabolic risk of Latino adults in primary care (Vida Sana): A randomized controlled trial. Contemporary Clinical Trials, 2016. 48: p. 30-40.

56. Visscher, B.B., et al., Evidence on the effectiveness of health literacy interventions in the EU: a systematic review. BMC Public Health, 2018. 18(1): p. 1414.

57. Tengland, P.A., Empowerment: a goal or a means for health promotion? Med Health Care Philos, 2007. 10(2): p. $197-207$.

58. Kouvonen, A., et al., Social support and the likelihood of maintaining and improving levels of physical activity: the Whitehall II Study. The European Journal of Public Health, 2012. 22(4): p. 514-518.

59. Pieroth, R., et al., Relationship between Social Support and Diet Quality in Middle-aged and Older Adults in the US. Journal of the Academy of Nutrition and Dietetics, 2017.

60. Legh-Jones, H. and S. Moore, Network social capital, social participation, and physical inactivity in an urban adult population. Social science \& medicine, 2012. 74(9): p. 1362-1367.

61. Chen, W.-L., et al., The impact of social capital on physical activity and nutrition in China: the mediating effect of health literacy. BMC Public Health, 2019. 19(1): p. 1713.

62. John, O. and D. Yadufashije, E-Health Biosensor Platform for Non-invasive Health Monitoring for the Elderly in Low Resource Setting. International Journal of Biomedical Engineering and Science (IJBES), 2018. 5(3/4).

63. Atallah, L., B. Lo, and G.-Z. Yang, Can pervasive sensing address current challenges in global healthcare? Journal of Epidemiology and Global Health, 2012. 2(1): p. 1-13.

\section{Table}

Page 17/18 
Figures

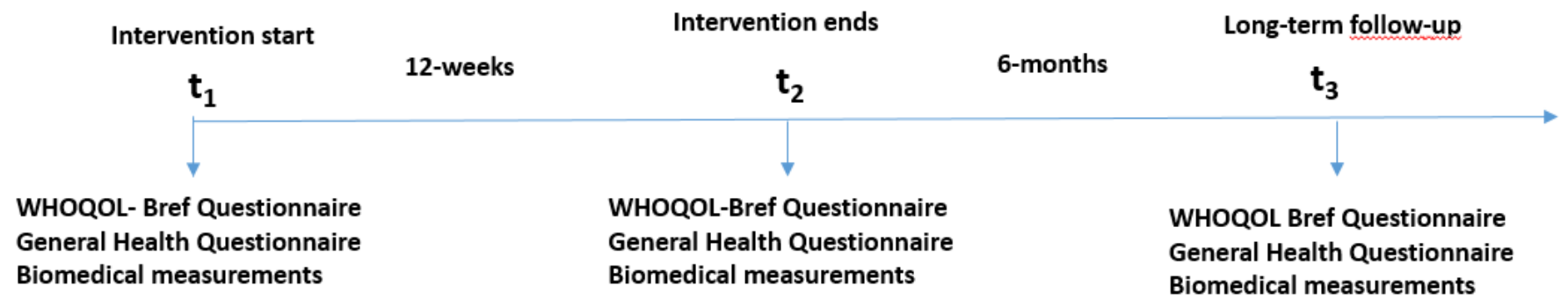

\section{Figure 1}

The timeline of events before and after the physical activity intervention 